\title{
IR spectra of paracetamol
}

\author{
U. Habiba*, A. Alam, S. Rahman, S. U. D. Shamim and A. A. Piya \\ Department of Physics, Mawlana Bhashani Science and Technology University, Santosh, Tangail-1902, Bangladesh
}

\begin{abstract}
Received: 14 September 2021

Revised: 14 October 2021

Paracetamol is a very popular medication used to treat pain and fever. IR spectra of paracetamol have been measured for powder crystals. Ab initio calculations of its equilibrium geometry and vibrational spectra were carried out for spectrum interpretation. Differences between the experimental IR spectra of crystalline samples have been analyzed. Variations of molecular structure from the isolated state to molecular crystal were estimated based on the difference between the optimized molecular parameters of free molecules and the experimental bond lengths and angles evaluated for the crystal forms of the title compounds. The role of hydrogen bonds in the structure of molecular crystals of paracetamol is investigated.
\end{abstract}

Accepted: 19 October 2021

DOI: https://doi.org/10.3329/bjsir.v56i4.57197

Keywords: Pharmaceuticals; $\mathrm{Ab}$ initio calculation; Molecular crystals; Hydrogen bond; Intermolecular interaction

\section{Introduction}

Paracetamol (acetaminophen) is widespread pharmaceuticals with anti-fever activities. The biological activity and the pharmaceutical properties of drugs are strongly dependent on their structure. The structural formulas and some physicochemical properties of these compounds have been known for decades. Detailed investigations of their crystal forms, however, were started in recent years. For paracetamol, three polymorphic modifications were described (Haisa et al., 1974; Haisa et al.,1976; Nichols and Frampton,1998; Szelagiewicz et al., 1999). Molecular spectroscopy methods, in particular, experimental IR spectroscopy, have long been successfully employed for structure investigations of complex molecular compounds. These techniques are especially effective when used in combination with direct methods of structural analysis in hydrogen bond investigations.

At present, few works reporting the IR spectra of paracetamol are available. Thus IR spectra have been published for three of its crystal modifications, and an assignment of the most intense bands has been suggested (Szelagiewicz et al., 1999). The first and, to the best of our knowledge, the single spectroscopic work with full quantum-chemical calculation of the structure and vibrational spectrum of paracetamol appeared in 1998 (Binev et al., 1998). Thevibrational spectrum calculated with a good (DFT/SDD) basis set and with appropriate scaling of frequencies was successfully correlated with the experimental IR spectrum of paracetamol. Full spectrum assignment was made based on the calculation using the shapes of normal vibrations in accordance with the potential energy distribution over internal coordinates.

The aim of the present work is theoretical and experimental spectroscopic investigation of free molecules andmolecular crystals of paracetamol to gain insight into the structure and role of hydrogen bonds in theirmolecular crystals.

*Corresponding author e-mail: bintehabib040@mbstu.ac.bd 


\section{Materials and methods}

Paracetamol commercial samples were purified by recrystallization from an ethanol solution. The orthorhombic modification of paracetamol was obtained from a melt according to the procedure described in (Politov et al., 2001).

IR spectra were recorded on a ShemadzuIRPrestige-21 with mid-near-far infrared measurement range Fourier Transformed IR spectrometer (resolution $4 \mathrm{~cm}^{-1}$ ) for $\mathrm{KBr}$ pellets (2 $\mathrm{mg}$ sample with $500 \mathrm{mg} \mathrm{KBr}$ ). Attempts were made to monitor the intermolecular interactions in solutions according to changes in the spectra. For spectrum measurements in the near IR range $\left(400 \mathrm{~cm}^{-1}-4000 \mathrm{~cm}^{-1}\right)$, was used. Diffuse scattering spectra of paracetamol powders were recorded, which were subsequently converted into absorption spectra.Ab initio calculation of equilibrium geometry and normal vibration frequencies for paracetamol molecules was carried out using the Gaussian-94/DFT program.

\section{Results and discussions}

$\mathrm{Ab}$ initio quantum-chemical calculation of the structure and vibrational spectra of paracetamolmolecules was carried out in a density functional theory (DFT) approximation using hybrid (B3LYP) potentials (Becke, 1993). The DFT method provides the best agreement with experiment for vibrational frequencies and is considered to be the mostsuitable technique for spectrum calculations of moderately large molecules (Johnson et al., 1993). The standard 6-31G* basis set was used. For geometry optimization for paracetamol, the Cartesian atomic coordinates obtained from structure determinationof the monoclinic modification were specified as initial data (Haisa et al., 1976). The optimized geometry of paracetamol with the $\mathrm{OH}$ groupreplaced by the ethyl fragment was given as the initial structure for geometry optimization of clonazepam. Frequency assignment for normal vibrations was fulfilled by analyzing atomic displacements in Cartesiancoordinates, by calculating the potential energy distribution over internal coordinates (bond lengths and angles, dihedral angles, and coordinates of bond departure from the molecular plane), and by calculating the potential and kinetic energydistribution over the molecular fragments $-\mathrm{CH}_{3},-\mathrm{C}=\mathrm{O},-\mathrm{NH},-\mathrm{C}_{6} \mathrm{H}_{4}$, and $-\mathrm{O}-\mathrm{H}$ (for paracetamol) or $-\mathrm{CH}_{2} \mathrm{CH}_{3}$ (forclonazepam), or over larger fragments: phenyl, amide, and-O-H or $-\mathrm{CH}_{2} \mathrm{CH}_{3}$. Optimization gave planar conformations (with the phenyl and amide fragments lying in the same plane) for bothmolecules (Fig. 1). The calculated normal vibration frequencies and their assignment are given in Table 1. Due to dissolution, bioavailability and absorption, the molecular form and crystal form of paracetamol impart differences in physicochemical and pharmacological properties.
Theoretical spectra of paracetamol:

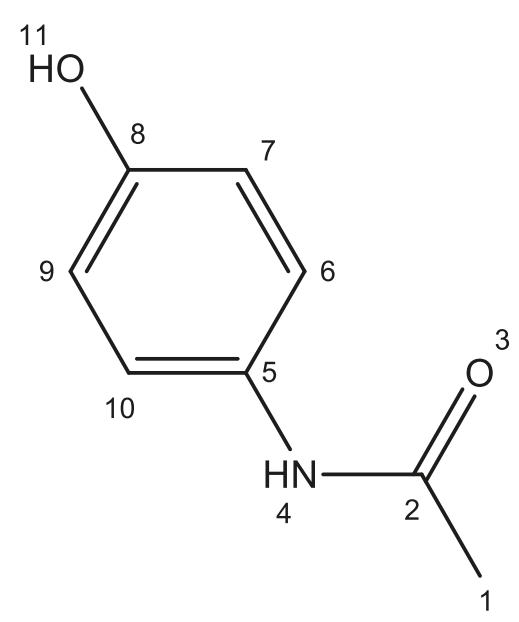

Structure of paracetamol

The X-H high-frequency vibrations above $2900 \mathrm{~cm}^{-1}$ (Table 1) are completely localized on the corresponding molecular fragments of paracetamol namely, on $-\mathrm{OH},-\mathrm{NH},-\mathrm{C}_{4} \mathrm{H}_{6}$, $-\mathrm{CH}_{3}$, and $-\mathrm{CH}_{2} \mathrm{CH}_{3}$. The nearly free rotation ofthe methyl group noted (Wilson and Struct, 1997) for the monoclinic modification of crystalline paracetamol is evidently also due to the minorchanges in the parameters of the methyl fragment in the molecular crystal compared to the free methyl group.

The frequencies in the range $1682 \mathrm{~cm}^{-1}-1530 \mathrm{~cm}^{-1}$ are due to the stretching vibrations of the phenyl ring; the highestfrequency is completely localized on the phenyl ring in both molecules, and the other frequencies are mixed with thevibrations of the amide fragment. The largest contribution to the potential energy of these mixed vibrations is from thevariation of the $\mathrm{NCH}$ bond angle in the plane of the molecule. For lower frequencies from this range, the contributions fromthe amide and phenyl fragments are approximately the same. Based on the potential energy distribution over the internalcoordinates, these vibrations are in a certain sense attributable to the band that is interpreted in experimental spectroscopy asthe second band of the amide group. It should be noted, however, that none of the vibrations in this range is localized on theamide fragment.

In the range $1500 \mathrm{~cm}^{-1}-1300 \mathrm{~cm}^{-1}$, the $\mathrm{C}-\mathrm{C}$ stretching vibrations of the phenyl group are mixed with thedeformation vibrations of the amide methyl fragments are also mixed with the deformation vibrations ofthe ethyl group. The potential energy of the low frequencies of this range has a contribution from the variation of the $\mathrm{CO}$ and $\mathrm{CN}$ bonds, but this contribu- 
tion is too low $(20 \%)$ to assign any of these frequencies to the stretching vibrations.

The vibrations in the range $1291 \mathrm{~cm}^{-1}-950 \mathrm{~cm}^{-1}$ are in-plane deformation vibrations of the $\mathrm{C}-\mathrm{H}$ bonds of the phenylring, which are mixed [except the $1155(1154) \mathrm{cm}^{-1}$ frequencies with the stretching and deformation vibrations of the amidefragment. Starting from $952 \mathrm{~cm}^{-1}$ for paracetamol, one can observe the out-of-plane deformationvibrations of the phenyl $\mathrm{C}-\mathrm{H}$ bonds; these are mixed with the deformation vibrations of the $\mathrm{C}-\mathrm{C}$ bonds accompanied by thedeparture of the carbon atoms from the plane of the phenyl ring. Some of these are completely localized on the phenylfragment, while the others are mixed with the deformation and out-of-plane vibrations of the amide group. The frequencies below $600 \mathrm{~cm}^{-1}$ correspond to the in-plane and out-of-plane (alteration of the dihedral angles between the planes of thephenyl and amide groups) vibrations of molecules and are not localized on any fragments.

Thus, our calculations enabled us to assign the calculated frequencies within the framework of the group frequencyconcept, which is conveniently used for interpreting the experimental data.

The calculated frequencies of free paracetamol molecules are similar to thefrequencies in the experimental spectra. Therefore, one can conclude that the calculated molecular parameters (bond lengths and angles, dihedral angles, and forcecon- stants) are similar to the corresponding parameters of free molecules.

Our DFT calculation is slightly better in reproducing the experimental frequencies of paracetamol than thecalculation of (Binev et al., 1998). The maximal divergence of the unscaled frequencies is $435 \mathrm{~cm}^{-1}$ in [14] and $96 \mathrm{~cm}^{-1}$ in our calculation. Itseemed useful to give our assignment of the calculated normal vibration frequencies for paracetamol (Table 1), although itdoes not differ fundamentally from (Binev et al., 1998)

For the spectra of solutions, the assignment of the experimental $3600 \mathrm{~cm}^{-1}$ and $3438 \mathrm{~cm}^{-1}$ absorption bands (ABs) tothe $\mathrm{OH}$ and $\mathrm{NH}$ stretching vibrations in paracetamol. The weak ABs above $3000 \mathrm{~cm}^{-1}$ are also unambiguously assigned to the $\mathrm{C}-\mathrm{H}$ stretching vibrationsof the phenyl ring, and the stronger bands above $2800 \mathrm{~cm}^{-1}$ are attributed to the stretching vibrations of the methyl and ethylgroups (Fig. 2, 1, 2; Table I).

The intermolecular interactions aremost conspicuous in this spectral region because of the displacement and broadening of the absorption bands caused byhydrogen bonding. Interpreting the spectral region above $2500 \mathrm{~cm}^{-1}$ is complicated by the presence of overtones andcomposite frequencies. In view of the Fermi resonance, the intensity of these bands may be anomalously high. The presenceof harmonic frequencies in great numbers in the spectra of paracetamol is

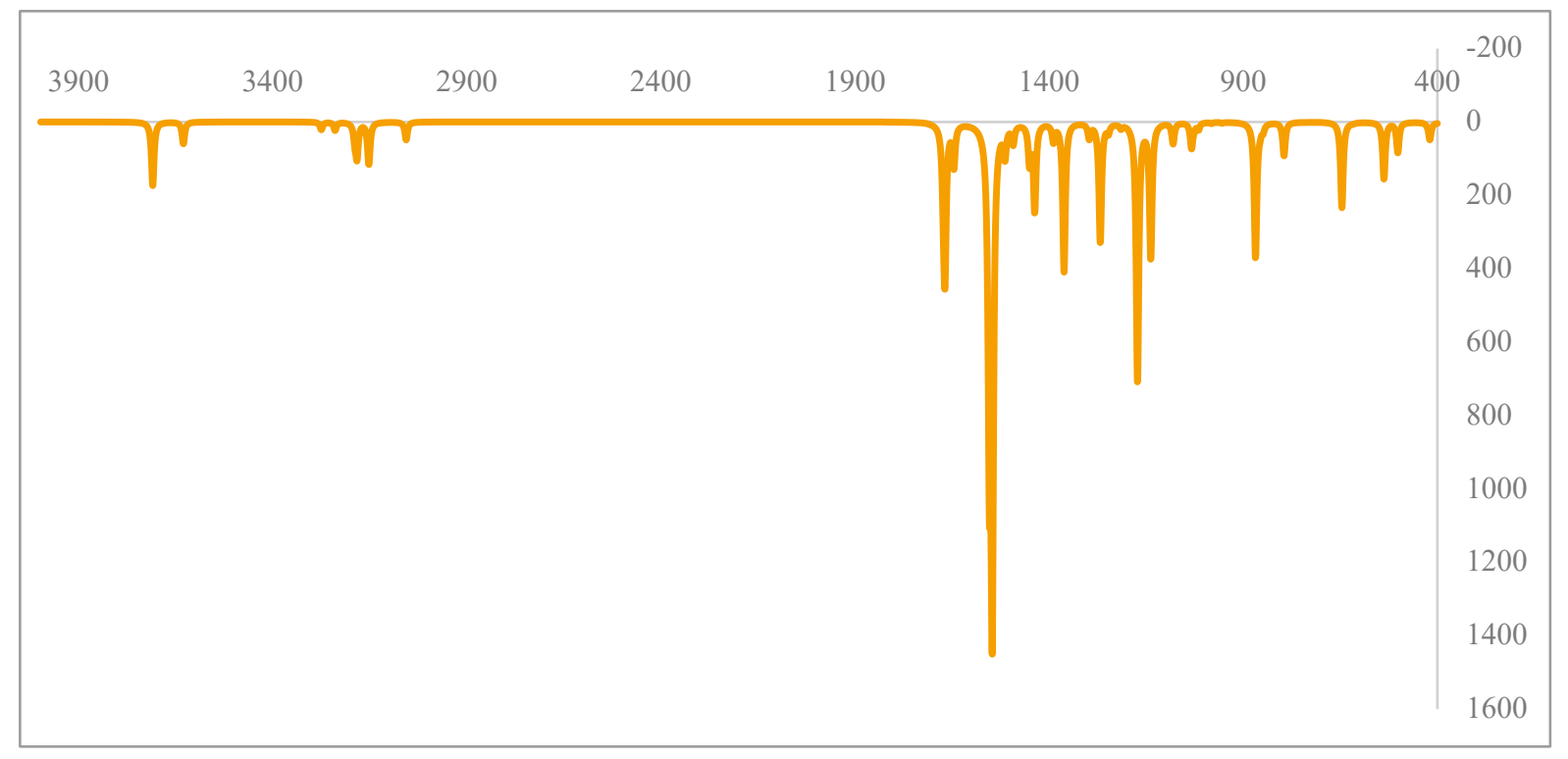

Fig. 1. Theoretical IR of paracetamol 


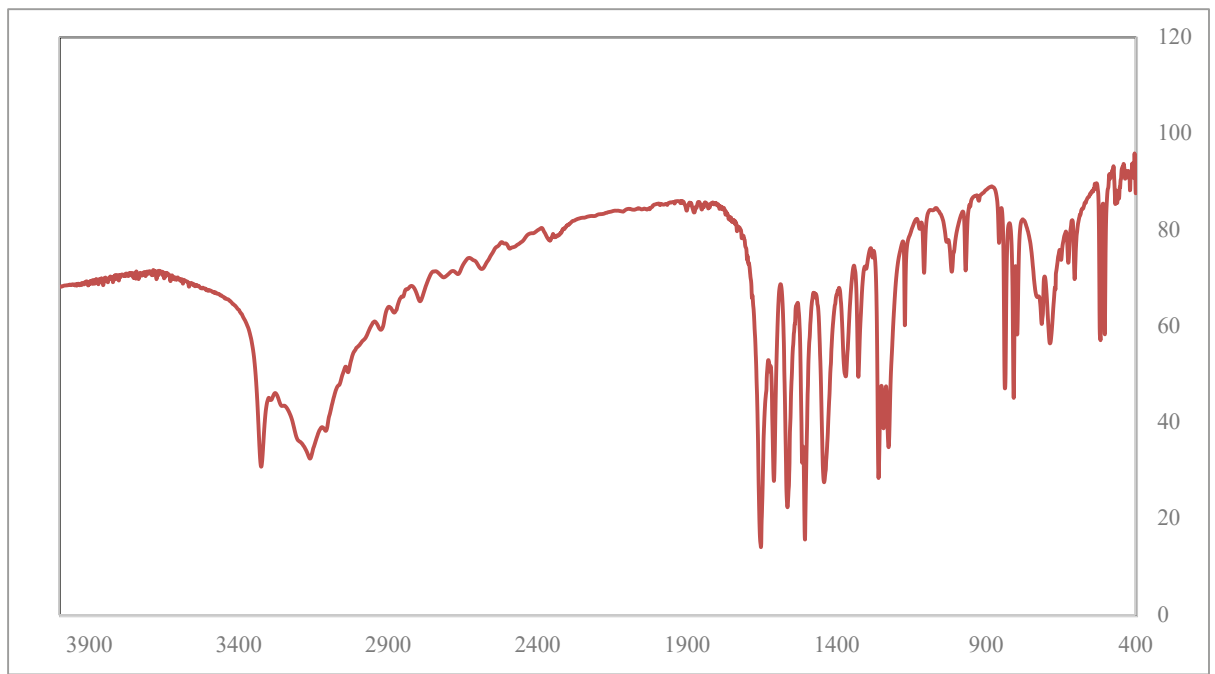

Fig. 2. Experimental IR of ACE

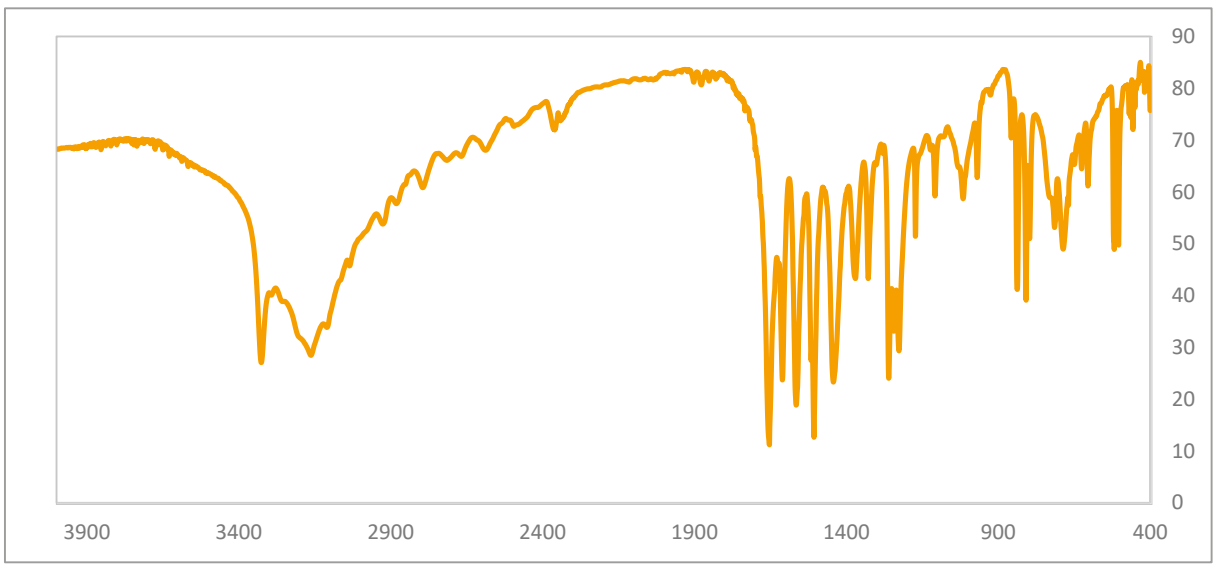

Fig. 3. Experimental IR of Fast

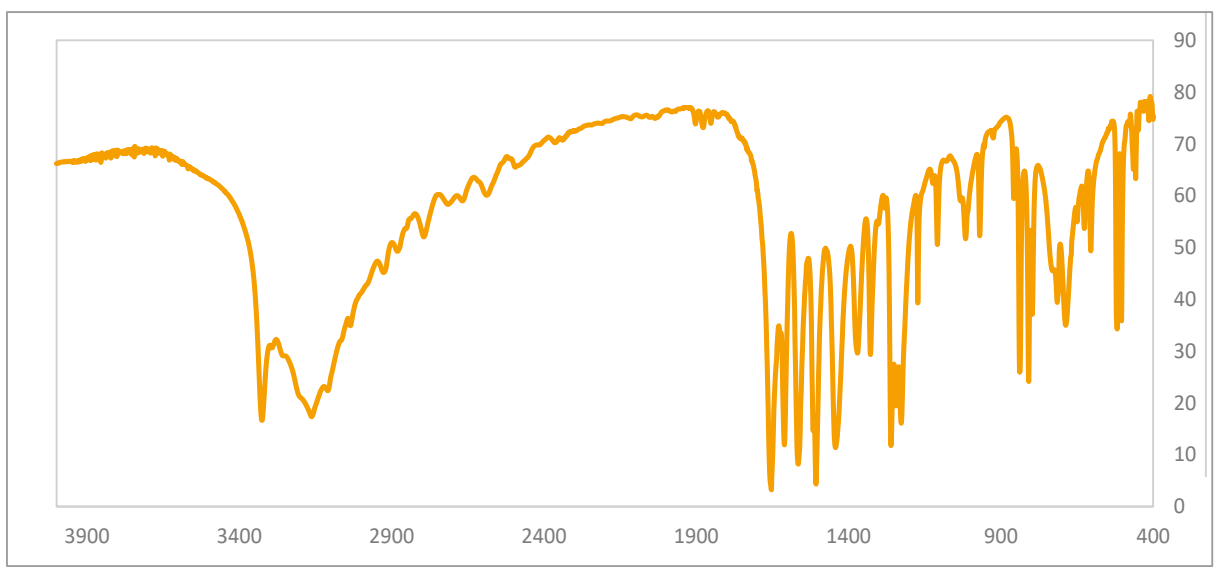

Fig. 4. Experimental IR of Napa 


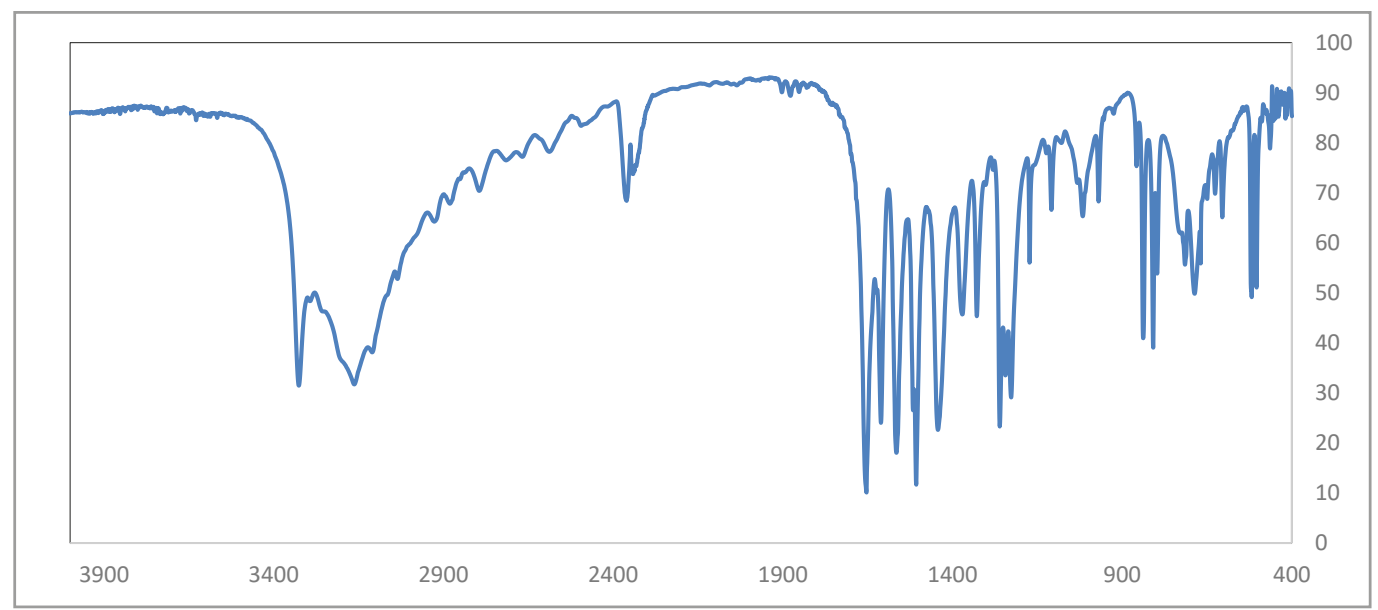

Fig. 5. Experimental IR of Glasco paracetamol

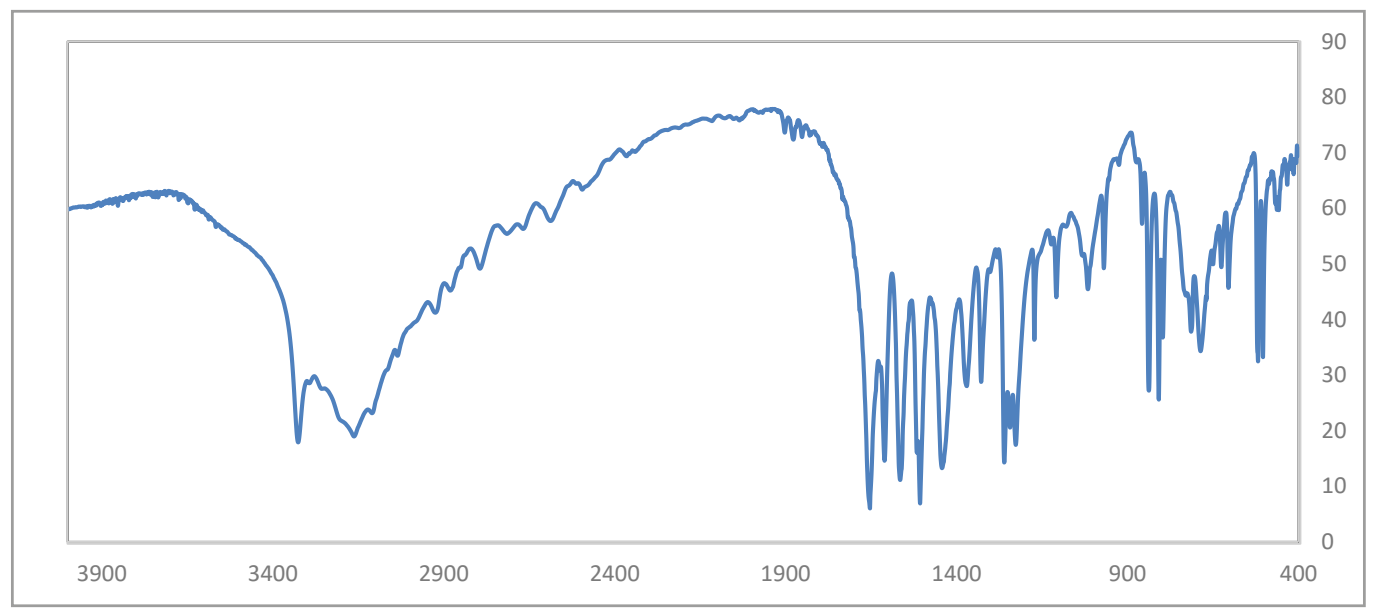

Fig. 6. Experimental IR of Tamen

also confirmed by theexperimental spectra of the crystalline powders in the near IR region (Fig. 4).

According to our calculation, the intense $1683 \mathrm{~cm}^{-1}$ band of a paracetamol solution and the $1679 \mathrm{~cm}^{-1}$ band of a clonazepam solution (nonpolar solvents in both cases) correspond to the first band of the amide group, more than $57 \%$ of theirpotential energy reflecting the state of the $\mathrm{C}=\mathrm{O}$ bond. In the spectra of the two crystal modifications of paracetamol andcrystalline clonazepam, the frequency of this vibration is $20 \mathrm{~cm}^{-1}-30 \mathrm{~cm}^{-1}$ lower than that in the spectra of the molecularforms. For the monoclinic modification of paracetamol, this is a single vibration band $\left(1654 \mathrm{~cm}^{-1}\right)$; for the orthorhombic modification, there are two bands (1667 $\mathrm{cm}^{-1}$ and $\left.1656 \mathrm{~cm}^{-1}\right)$.
In the range $1625 \mathrm{~cm}^{-1}-1000 \mathrm{~cm}^{-1}$, the spectra of the solutions and crystal forms of paracetamol (Fig. 3, 1, 3, 4) differ mainly in the relative intensity and in the number of absorption bands, while the position of the fundamental bands changes insignificantly and the experimental spectra are rather close to the theoretical spectra (Table I).

Below $1000 \mathrm{~cm}^{-1}$, the spectra of solutions could not be obtained for any of compounds because of solventabsorption and the narrow spectral ranges of solvent transparency, leading to unreliable spectrum subtraction. Therefore inthe range $1000 \mathrm{~cm}^{-1}-400 \mathrm{~cm}^{-1}$, Fig. 3 shows only the spectra of the crystal forms of the compounds. The assignment of the relevant absorption bands in the spectra of the crystalline samples based on the assignments in the theoretical spectra 
Table I. Comparison of theoretical and experimental vibrational frequencies of paracetamol

\begin{tabular}{|c|c|c|c|}
\hline Serial No. & Types of Vibration & Theoretical $\left(\mathrm{cm}^{-1}\right)$ & Experimental $\left(\mathrm{cm}^{-1}\right)$ \\
\hline 1 & $\mathrm{~V}_{\mathrm{OH}}$ & 3710 & 3325 \\
\hline 2 & $\mathrm{~V}_{\mathrm{NH}}$ & 3631 & 3292 \\
\hline 3 & $\mathrm{~V}_{\mathrm{PhH}}$ & 3275 & 3254 \\
\hline 4 & $\mathrm{~V}_{\mathrm{PhH}}$ & 3240 & 3198 \\
\hline 5 & $\mathrm{~V}_{\mathrm{PhH}}$ & 3184 & 3162 \\
\hline 6 & $\mathrm{~V}_{\mathrm{CH} 3}$ & 3153 & 3107 \\
\hline 7 & $\mathrm{~V}_{\mathrm{CH} 3}$ & 3056 & 3062,3034 \\
\hline 8 & $\mathrm{~V}_{\mathrm{Ph}(\mathrm{C}=\mathrm{C})}$ & 1669 & 1654 \\
\hline 9 & $\mathrm{~V}_{\mathrm{C}=0}$ & 1668 & 1610 \\
\hline 10 & $\mathrm{~V}_{\mathrm{C}=0+\mathrm{CNC}+\mathrm{Ph}}$ & 1452 & 1564,1506 \\
\hline 11 & $\mathrm{~V}_{\mathrm{CH} 3}$ & 1438 & 1440 \\
\hline 12 & $\mathrm{~V}_{\mathrm{Ph}(\mathrm{C}=\mathrm{C})}$ & 1389 & 1369 \\
\hline 13 & $\mathrm{~V}_{\mathrm{PhH}}$ & 1362 & 1328 \\
\hline 14 & $\mathrm{~V}_{\mathrm{NH}(\text { Bening })}$ & 1297 & \\
\hline 15 & $\mathrm{~V}_{\mathrm{C}-0}$ & 1269 & 1260 \\
\hline 16 & $\mathrm{~V}_{\mathrm{NCH}(\text { Bening })}$ & 1215 & 1243 \\
\hline 17 & $\mathrm{~V}_{\mathrm{CN}}$ & 1173 & 1226 \\
\hline 18 & $\mathrm{~V}_{\mathrm{Ph}(\text { Ring })}$ & 1139 & 1172 \\
\hline 19 & $\mathrm{~V}_{\mathrm{CH} 3}$ & 1081 & 1108 \\
\hline 20 & $\mathrm{~V}_{\mathrm{Ph}(\text { Ring deformation })}$ & 1033 & 1015 \\
\hline 21 & $\mathrm{~V}_{\mathrm{Ph} \text { (Ring deformation) }}$ & 863 & 808 \\
\hline 22 & $\mathrm{~V}_{\mathrm{Ph}(\text { Ring deformation) }}$ & 795 & 796 \\
\hline 23 & $\mathrm{~V}_{\mathrm{Ph} \text { (Ring deformation) }}$ & 646 & 686 \\
\hline 24 & $\mathrm{~V}_{\mathrm{Ph} \text { (Ring deformation) }}$ & 538 & 517 \\
\hline 25 & $\mathrm{~V}_{\mathrm{Ph} \text { (Ring deformation) }}$ & 501 & 503 \\
\hline
\end{tabular}

seems tobe quite correct because of good agreement between the theoretical and experimental frequencies (Table I).

Spectral features indicative of intermolecular interactions. The molecular crystals of paracetamol are suitable model systems for investigating intermolecular interactions. The paracetamol molecule includes two potentialdonor $(\mathrm{N}-\mathrm{H}$ and $\mathrm{O}-\mathrm{H})$ and two acceptor $(\mathrm{C}=\mathrm{O}$ and $\mathrm{H}-\mathrm{O})$ groups. The
$\mathrm{OH}$ group is both protondonor and acceptor $(-\mathrm{NH} \ldots \mathrm{OH} \ldots \mathrm{O}=\mathrm{C}-)$, while the $\mathrm{NH}$ group is a proton donor alone.

The difference between the optimized parameters of the free paracetamol and theexperimental bond lengths and angles of their crystal forms is associated with the presence of hydrogen bond systems in thecrystals of these compounds (Haisa 
et al., 1974; Haisa et al.,1976; Yuasa and Akutagava, 1996; Nichols and Frampton, 1998; Szelagiewicz et al., 1999; Hendriksen et al., 1998; Naumov et al., 1998; Wilson and Struct,1997; Wilson et al., 1997; Wilson and Kristallogr, 2000; Boldyreva et al., 2000; Boldyreva et al., 2002).

The difference between the spectra of crystalline powders and those of diluted solutions of paracetamol, which is especially conspicuous in the region of the $\mathrm{X}-\mathrm{H}$ stretching vibrations, is a spectral indication to thepresence of a system of hydrogen bonds in paracetamol and clonazepam crystals.

The large shifts of these frequencies compared to the spectra of solutions, as well as the complex shape of theabsorption contours, point to the presence of a system of strong hydrogen bonds ( $\mathrm{NH} \ldots \mathrm{O}$ and $\mathrm{OH} \ldots \mathrm{O})$ in the molecularcrystals of both modifications of paracetamol and $\mathrm{NH} . . . \mathrm{O}$ in the molecular crystals of clonazepam. This agrees with the resultsof diffraction studies (Haisa et al., 1974; Haisa et al., 1976; Yuasa and Akutagava, 1996; Nichols and Frampton,1998 Hendriksen et al., 1998; Naumov et al., 1998; Wilson and Struct, 1997; Wilson et al., 1997; Wilson and Kristallogr, 2000; Boldyreva et al., 2000; Boldyreva et al., 2002) including studies at reduced temperatures and elevated pressures.

The lowering of the VXH frequency due to hydrogen bonding compared to the spectrum of the free molecule is adirect measure of hydrogen bond strength. Therefore, one can assume that in the monoclinic modification of paracetamol, the-O-H...O hydrogen bonds $\left(\square \mathrm{VOH}=440 \mathrm{~cm}^{-1}\right)$ are slightly stronger than those in the orthorhombic modification $\left(\mathrm{VOH}=400 \mathrm{~cm}^{-1}\right)$. This agrees with the conclusions based on the diffraction analysis of the geometrical parameters of hydrogenbonds (Boldyreva et al., 2002; Boldyreva et al., 2002).

Similarly, from the shifts of the VNH frequencies ( $\square \mathrm{VNH}=$ $110 \mathrm{~cm}^{-1}$ ) one can assume that in both crystal modificationsof paracetamol, the $-\mathrm{N}-\mathrm{H} . . . \mathrm{O}$ hydrogen bonds are approximately equal in stability and are less stable than the $\mathrm{N}-\mathrm{H}$...Ohydrogen bonds in clonazepam crystals $(\mathrm{\square VNH}=$ $153 \mathrm{~cm}^{-1}$ ). As intermolecular hydrogen bonding in the latter is only possible to $\mathrm{NH}$ groups, one would expect that the $\mathrm{NH}$ stretching vibration frequency will decrease more drastically compared to thespectrum of the free molecule. Indeed, in the crystal forms of paracetamol, the VNH frequency has a 44 $\mathrm{cm}-1$ smaller shift thanin clonazepam crystals relative to the position of this frequency in the molecular state that is free from hydrogen bonds.
The $\mathrm{C}=\mathrm{O}$ bond length was calculated to be $1.226 \AA$ (Fig. 1) for the optimized structure of free paracetamol and clonazepam molecules, $1.235 \AA$ for monoclinic paracetamol, and $1.241 \AA$ for crystalline clonazepam. The larger $\mathrm{C}=\mathrm{O}$ bondlength and the correspondingly decreased $\mathrm{VC}=\mathrm{O}$ frequency unambiguously indicate that hydrogen bonding leads to aredistribution of electron density.

In the spectra of both crystalline modifications of paracetamol and crystalline clonazepam, the frequencies in therange $1660 \mathrm{~cm}^{-1}-1640 \mathrm{~cm}^{-1}$, reflecting the state of the $\mathrm{C}=\mathrm{O}$ bond (denoted for simplicity $\mathrm{VC}=\mathrm{O}$ ), are $20 \mathrm{~cm}^{-1}-30$ $\mathrm{cm}-1$ lowerthan in the spectra of the molecular form. This is another indication to strong intermolecular interactions involving the $\mathrm{C}=\mathrm{Obond}$ in crystals.

We traced the effect of intermolecular interactions on the $\mathrm{V}$ $\mathrm{C}=\mathrm{O}$ frequency in the spectra of DMSO solutions ofparacetamol and clonazepam. The $\mathrm{VC}=\mathrm{O}$ frequency was slightly shifted in both paracetamol and clonazepam solutions dependingon the solution concentration; it was roughly the same-around $1670 \mathrm{~cm}^{-1}$, which is lower than in the molecular form andhigher than in crystal forms. Probably, the formation of hydrogen bonds between the $\mathrm{S}=\mathrm{O}$ group of DMSO and the $\mathrm{NH}$ and $\mathrm{OH}$ groups of paracetamol, as well as the $\mathrm{NH}$ group of clonazepam, also leads to an electron density redistribution on the $\mathrm{C}=\mathrm{O}$ bond, which is manifested as the decreased $\mathrm{VC}=\mathrm{O}$ frequency.

The larger shift of $\mathrm{VC}=\mathrm{O}$ in the monoclinic form of paracetamol versus the orthorhombic form relative to the samefrequency in a molecule that is free from hydrogen bonds also points to stronger hydrogen bonds in the monoclinicmodification of paracetamol.

\section{Conclusion}

The calculated molecular parameters (bond lengths and angles, dihedral angles and force constants) are similar to the corresponding parameters of free molecules. The intermolecular interactions are most conspicuous in this spectral region because of the displacement and broadening of the absorption bands caused by hydrogen bonding. The difference between the spectra of crystalline powders and those of diluted solutions of Paracetamol which is specially clear view in the region of X-H stretching vibrations, is a spectral indication to the presence of a system of hydrogen bonds in paracetamol. The $\mathrm{VC}=\mathrm{O}$ frequency was slightly shifted in Paracetamol solutions depending on the solution concentration; it was roughly same around $1670 / \mathrm{cm}$ which is lower than in the molecular form and higher than in crystal forms. 


\section{References}

Becke AD (1993), A new mixing of Hartree-Fock and local density-functional theories, J. Chem. Phys. 98: 5648. DOI: org/10.1063/1.464304

Binev IG, Vassileva-Bouadjieva P and Binev YI (1998), Experimental and ab initio MO studies on the IR spectra and structure of 4-hydroxyacetanilide (paracetamol), its oxyanion and dianion, J. Mol. Struct. 447: 235-246. DOI: org/10.1016/ S0022-2860(98)00302-0

Boldyreva EV, Shakhtshneider TP and Ahsbahs H (2002), The role hydrogen bonds in the pressure-induced structural distortion of 4-hydroxyacetanilide crystals, Polish J. Chem. 76: 1333-1346.

Boldyreva EV, Shakhtshneider TP and Ahsbahs H (2002), Effect of high pressure on the polymorphs of paracetamol, J. Therm. Anal. Calorim. 68: 437-452.

Boldyreva EV, Shakhtshneider TP and Vasilchenko MA (2000), Anisotropic crystal structure distortion of the monoclinic polymorph of acetaminophen at high hydrostatic pressures, Acta Crystallogr. B56: 299-309. DOI: org/10.1107/S0108768199013634

Haisa M, Kashino S, Kawai R and Meda H (1974), The orthorhombic form of p-hydroxyacetanilide, Acta Crystallogr. B30: 2510-2512. DOI: org/10. $1107 / \mathrm{S} 0567740874007473$

Haisa M, Kashino S, Kawai R and Meda H (1976), The monoclinic Form of p-Hydroxyacetanilide, ibid. B32: 1283-1285. DOI: org/10.1107/S0567740876012223

Hendriksen BA, Grant DJW, Meenan P and Green DA (1998), Crystallisation of paracetamol (acetaminophen) in the presence of structurally related substances, J. Crystal Growth 183: 629-640. DOI: org/10.1016/S0022-0248(97)00488-0

Johnson BG, Gill PMW Pople and Pople JA (1993), The performance of a family of density functional methods, ibid. 98: $5612 \quad-5618$. DOI: org/10.1063/1.464906

Naumov DYu, Vasilchenko MA and Howard JAK (1998), The monoclinic form of acetaminophen at $150 \mathrm{~K}$, Acta Crystallogr. C54: 653-655. DOI: org/10.1107/ S0108270197018386

Nichols G and Frampton CS (1998), Physicochemical characterization of the orthorhombic polymorph of paracetamol crystallized from solution, J. Pharm. Sci. 87: 684-693. DOI: org/10.1021/js970483d

Politov AA, Kostrovskii VG and Boldyrev VV (2001), Conditions of preparation crystallization of amorphous paracetamol, Zh. Fiz. Khim. 75(11): 2062-2071.

Szelagiewicz M, Marcolli C, Cianferani S (1999), In Situ Characterization of Polymorphic Forms: The Potential of Raman Techniques, J. Therm. Anal. Calorim. 57: 23-43. DOI: org/10.1023/ a:1010184805966

Wilson CC and Kristallogr Z (2000), Variable temperature study of the crystal structure of paracetamol (P-hydroxyacetanilide) by single crystal neutron diffraction 215: 693-701. DOI: org/10.1524/ zkri.2000.215.11.693

Wilson CC, Shankl and Florence AJ and Frampton CS (1997), Single-crystal neutron diffraction of bio-active small molecules, Physica B234-236: 34-36. DOI: org/10.1016/S0921-4526(96)00889-7

Wilson CC and Struct J Mol (1997), Neutron diffraction of p-hydroxyacetanilide (Paracetamol): libration or disorder of the methyl group at $100 \mathrm{~K}$, Journal of molecular structure 405(2-3): 207-217. DOI: org/10.1016/S0022-2860(96)09593-2

Yuasa H and Akutagava M (1996), Studies on internal structure of tablets.VI. Stress dispersion in tablets by excipients, Chem. Pharm. Bull. 44(2): 378-382. 